\title{
Morphologic characterization of osteosarcoma growth on the chick chorioallantoic membrane
}

\author{
Maurice Balke ${ }^{1 * \dagger}$, Anna Neumann ${ }^{2 \dagger}$, Christian Kersting $^{3}$, Konstantin Agelopoulos $^{2}$, Carsten Gebert ${ }^{4}$, \\ Georg Gosheger ${ }^{1}$, Horst Buerger ${ }^{3}$, Martin Hagedorn ${ }^{5}$
}

\begin{abstract}
Background: The chick chorio-allantoic membrane (CAM) assay is a commonly used method for studying angiogenic or anti-angiogenic activities in vivo. The ease of access allows direct monitoring of tumour growth by biomicroscopy and the possibility to screen many samples in an inexpensive way. The CAM model provides a powerful tool to study effects of molecules, which interfere with physiological angiogenesis, or experimental tumours derived from cancer cell lines. We therefore screened eight osteosarcoma cell lines for their ability to form vascularized tumours on the CAM.

Findings: We implanted 3-5 million cells of human osteosarcoma lines (HOS, MG63, MNNG-HOS, OST, SAOS, SJSA1, U2OS, ZK58) on the CAM at day 10 of embryonic development. Tumour growth was monitored by in vivo biomicroscopy at different time points and tumours were fixed in paraformaldehyde seven days after cell grafting. The tissue was observed, photographed and selected cases were further analyzed using standard histology. From the eight cell lines the MNNG-HOS, U2OS and SAOS were able to form solid tumours when grafted on the CAM. The MNNG-HOS tumours showed the most reliable and consistent growth and were able to penetrate the chorionic epithelium, grow in the CAM stroma and induce a strong angiogenic response.

Conclusions: Our results show that the CAM assay is a useful tool for studying osteosarcoma growth. The model provides an excellent alternative to current rodent models and could serve as a preclinical screening assay for anticancer molecules. It might increase the speed and efficacy of the development of new drugs for the treatment of osteosarcoma.
\end{abstract}

\section{Introduction}

Osteosarcoma is the most common primary malignant bone tumour that usually affects children and adolescents. After the introduction of cytotoxic polychemotherapy to the treatment of osteosarcoma tremendous advances were achieved, increasing the survival rate from under $20 \%$ to over $60 \%$ [1]. But over the past 20 years no substantial improvements were made. There is still a high failure rate especially when metastases are present[2]. It is therefore of critical importance to identify new targets and new molecules with efficient antitumour activity. New targets might be identified by large-scale microarray analysis or array-based genomic hybridization[3] to identify different gene expressions in

\footnotetext{
* Correspondence: maurice.balke@web.de

+ Contributed equally

'Department of Orthopaedic Surgery, University of Muenster, Muenster, Germany
}

patient samples or suitable in vivo animal models. It is expected that anti-angiogenic agents will have clinical benefits for patients with osteosarcoma, probably by reducing metastasis[4]. Thus especially models that allow precise monitoring of tumour angiogenesis might be promising in finding new targets to treat osteosarcoma[5].

An in vivo assay to serve these purposes is the chick chorio-allantoic membrane (CAM) assay. The CAM is formed on embryonic day $4-5$ by fusion of the chorion with the allantoic vesicle[6]. The resulting membrane consists of two mesodermal layers: the somatic mesoderm of the chorion and the splanchnic mesoderm of the allantois. In this structure, an extremely dense vascular network develops with bigger vessels located within the mesoderm and the capillaries situated directly under or within a very thin ectodermal layer. The physiological role of the CAM is to serve as a respiratory 
organ until hatching, to store waste products and to absorb calcium from the shell for bone development[7]. On the molecular level critical genes which participate in the vascularisation of complex human tissues such as placenta and the lung are significantly regulated during the CAM vascular development[8]. The CAM assay is characterized by several major advantages such as the ease of access, the extensive vascularisation and the relatively simple experimental approach. This opens up the possibility to screen many samples in an inexpensive way[9].

Since its use to demonstrate normal embryonic blood vessel development more than 100 years ago, the CAM served as a host for transplantations of embryonic tissue as well as for bacteria and viruses. During the last 20 years the CAM is extensively used in angiogenesis research but a reliable bone tumour model has not yet been reported.

Here we present the results of the screening of the human osteosarcoma cell lines HOS, MG63, MNNGHOS, OST, SAOS, SJSA1, U2OS and ZK58 for their use in the CAM assay and provide evidence that the MNNG-HOS cell line reproducibly simulates key features of human osteosarcoma growth.

\section{Materials and methods \\ Cell culture}

Eight osteosarcoma cell lines (HOS, MG63, MNNGHOS, OST, SAOS, SJSA1, U2OS, ZK58) were used in this study. All cell lines were cultured in RPMI 1640 (E15-840, PAA Austria) supplemented with 10\% Fetal Bovine Serum (FBS Gold, A15-649, PAA Austria) and $1 \%$ penicilline/streptomycine (P11-010, PAA Austria) at $37^{\circ} \mathrm{C}$ in a humidified $5 \% \mathrm{CO}_{2}$ incubator. Prior implantation, cell suspensions were prepared by detaching cells with trypsin/EDTA (L11-004, PAA Austria). Cells were centrifuged at $1200 \mathrm{rpm}$ for $5 \mathrm{~min}$, washed twice in culture medium and resuspended in medium at a final concentration of 3 to 5 million cells per $20 \mu \mathrm{l}[10]$.

\section{CAM assay}

Fertilized white leghorn chicken eggs (Lohmann Tierzucht $\mathrm{GmbH}$, Cuxhaven, Germany) were incubated at a humidity of $70 \%$ and $37^{\circ} \mathrm{C}$. On day 3 of incubation, a round window was cut into the shell after removal of $2-3 \mathrm{ml}$ of albumen allowing detachment of the embryo from the eggshell. Normal development was verified and embryos with malformations or dead embryos were excluded. The window was sealed with tape and the eggs were returned to the incubator. On day 10 of development, small plastic rings made out of Thermanox ${ }^{\mathrm{ma}}$ discs were placed on the CAM and $25 \mu \mathrm{l}$ of medium containing different cell lines were deposited into the rings after gentle laceration of the CAM surface. The number of CAMs implanted for each cell line is indicated in Table 1. CAMs were examined daily until day 17 and photographed in ovo with a digital camera (Olympus E330) attached to a stereomicroscope. CAMs were checked for tumour growth. Positive tumour development ("+" tumours) was reported when tumour angiogenesis was visible and when tumours were bigger than $2 \mathrm{~mm}$. All other tumours were classified as ("-"). The estimated tumour volume was calculated (according to Hagedorn et al 2005[10]) by the following formula: $\mathrm{V}=4$ / $3^{*} \pi{ }^{*} \mathrm{r}^{3}(\mathrm{r}=1 / 2$ * square root of diameter $1 *$ diameter 2$)$. Frequently several independent tumour nodules developed. However for quantification only the biggest nodule was taken. Only CAMs still alive at day 17 were included in this analysis.

\section{Statistical analysis}

To determine if osteosarcoma growth on the CAM was associated with increased embryonic death, a $2 \times 2$ contingency table test (Fisher's exact test) was used for each cell line compared to control CAMs.

\section{Histology}

On embryonic day 17 , a few $\mathrm{ml}$ of $4 \%$ paraformaldehyde were put onto the CAM after photo documentation. After 20 min the window was carefully enlarged using scissors without destroying the CAM. Areas containing the tumour were cut out and transferred into culture discs. All tumours were evaluated and relevant samples were embedded in paraffin and processed for sectioning. Embedded tumours were cut into $10 \mu \mathrm{m}$ sections, stained with hematoxylin-eosin and further analysed by standard light microscopy (Leica DM2500 with Leica EC3 camera).

\section{Results}

From the eight cell lines tested only the MNNG-HOS, U2OS and SAOS line consistently (= more than in 50\% of the cases alive at day 17) formed vascularized tumours of more than $2 \mathrm{~mm}$ in size (Figure 1). In all other cell lines, the tumours where either smaller or did not develop at all (Table 1). Grafting of the U2OS and SAOS cell lines was significantly associated with increased embryonic death, compared to non-grafted CAMs (P-values: 0.0294 and 0.0008, respectively).

MNNG-HOS, U2OS and SAOS tumours revealed a reproducible growth pattern after implantation of the cells. After 4 days, a vascularized tumour became apparent. Growth and vascularization of the tumour steadily progressed until day 7 as evidenced by biomicroscopy (Figure 2A-C). In some cases of MNNG-HOS tumours, growth was associated with bleeding (Figure 2C-E). Furthermore, MNNG-HOS tumours showed an invasive growth pattern and were able to penetrate the CAM and grow underneath it. This was not observed in the 
Table 1 Overview of tested osteosarcoma cell lines

\begin{tabular}{|c|c|c|c|c|c|c|c|}
\hline Cell line & Number of grafted CAMs & Embryos died & Number of - tumours & Number of + tumours & Ratio +/- & $\%$ dead & $P$-value* \\
\hline MNNG-HOS & 23 & 6 & 6 & 11 & $11 / 17$ & 26.1 & NS \\
\hline U2OS & 21 & 11 & 5 & 5 & $5 / 10$ & 52.4 & 0.0294 \\
\hline SAOS & 20 & 14 & 3 & 3 & $3 / 6$ & 70 & 0.0008 \\
\hline OST & 8 & 2 & 5 & 1 & $1 / 6$ & 25 & NS \\
\hline MG63 & 14 & 7 & 4 & 1 & $1 / 7$ & 50 & NS \\
\hline HOS & 20 & 5 & 13 & 2 & $2 / 15$ & 25 & NS \\
\hline ZK58 & 35 & 11 & 21 & 3 & $3 / 24$ & 31.4 & NS \\
\hline SJ-SA-1 & 11 & 2 & 9 & 0 & $0 / 9$ & 18.2 & NS \\
\hline Controls & 26 & 5 & & & & 19.2 & \\
\hline
\end{tabular}

$\mathrm{n}=$ number, - = no tumour/tumour $\leq 2 \mathrm{~mm},+=$ vascularized tumour $>2 \mathrm{~mm}$

${ }^{*}$ Fisher's exact test (cell line vs. controls); $N S=$ not significant

U2OS and SAOS tumours that stayed on the surface of the CAM or within the membrane. This became clearly apparent when the membrane was cut out after fixation and turned upside down (Figure 2D-G). The surrounding vessels were attracted towards the tumour tissue. At higher magnification, blood flow could be observed, a direct evidence of the functionality of the tumour capillaries (data not shown). Biomicroscopy of the tumours revealed a very rich vascularisation showing signs of active sprouting angiogenesis (Figure 2G).

Standard histology with hematoxylin-eosin staining confirmed the rich vascularisation of the tumours with capillaries sprouting out of the CAM into the tumour (Figure 3A, B). Nucleated chick erythrocytes were present in the capillaries (Figure $3 \mathrm{C}$ ). The tumours contained stromal cells with disseminated uncharacterized macrophages. Areas of angiogenesis, necrosis and haemorrhage were present, a typical feature of human osteosarcoma (Figure 3B $+\mathrm{C}$ ). Osteoid formation did not occur in any cell line. Controls with medium alone did not show any tissue growth, inflammatory reaction or vascular response.

\section{Discussion}

Experimental in vivo tumour models are essential for comprehending the dynamic process of human cancer progression, identifying therapeutic targets, and evaluating antitumour drugs. Besides the promising efforts made in the research on osteosarcoma using in vitro assays[11] there is a lack of potent and reproducible in vivo models to evaluate new therapies in a pre-clinical setting.

The chick chorioallantoic membrane assay is a commonly used method for studying angiogenic or antiangiogenic activities in vivo[12]. Although first tumour transplantations to the CAM were described more than 100 years ago[13] CAM tumour models are still rarely developed and characterized, compared to murine models[14]. Taking into account the easy access, relatively simple experimental approach and the natural immonodeficient environment of the developing embryo (for review see[15]) its rare use for tumour grafting is surprising. Recently, a reliable experimental glioblastoma CAM model using the human U87 cell line has been established[10]. The experimental glioma model simulates key features of human glioma growth in a few days. Treatment with the tyrosine kinase inhibitors Gleevec (imatinib) or PTK787/ZK 222584, siRNAmediated knock down of Vascular Endothelial Growth Factor (VEGF) and/or IL6[16,17] potently inhibited tumour angiogenesis and growth in this model.

Another group inoculated single cell suspensions of LNCaP, PC-3 and Tsu-Pr1 human prostatic cancer cell lines on the chorio-allantoic membrane. They demonstrated a reliable tumour growth allowing the evaluation of proliferation and apoptosis induction after intravascular or topic application of anticancer drugs[18].

There are very few publications about the use of the CAM assay in human bone or soft tissue sarcoma $[19,20]$. The literature does not provide any reports that specifically characterise the tumour forming potential of different human osteosarcoma cell lines. Therefore, we established a protocol allowing monitoring of the growth of several osteosarcoma lines on the CAM. The MNNG-HOS, U2OS and SAOS cell lines consistently developed vascularized tumours after 4 days, which then progressively consolidated throughout the growth process. All tumours were derived from established human osteosarcoma cell lines [21-24] and were more or less able to form a solid tumour, but only the MNNG-HOS, SAOS and U2OS reached the consistency as well as average tumour size (Figure 1G) to allow further investigations. The MNNG-HOS cells clearly provided the most reliable and consistent results. The reasons for these differences remain speculative. The difference of up to two million cells between CAM's from different experiments might partly explain the size variances, but it is rather unlikely as this would affect all cell lines. It 

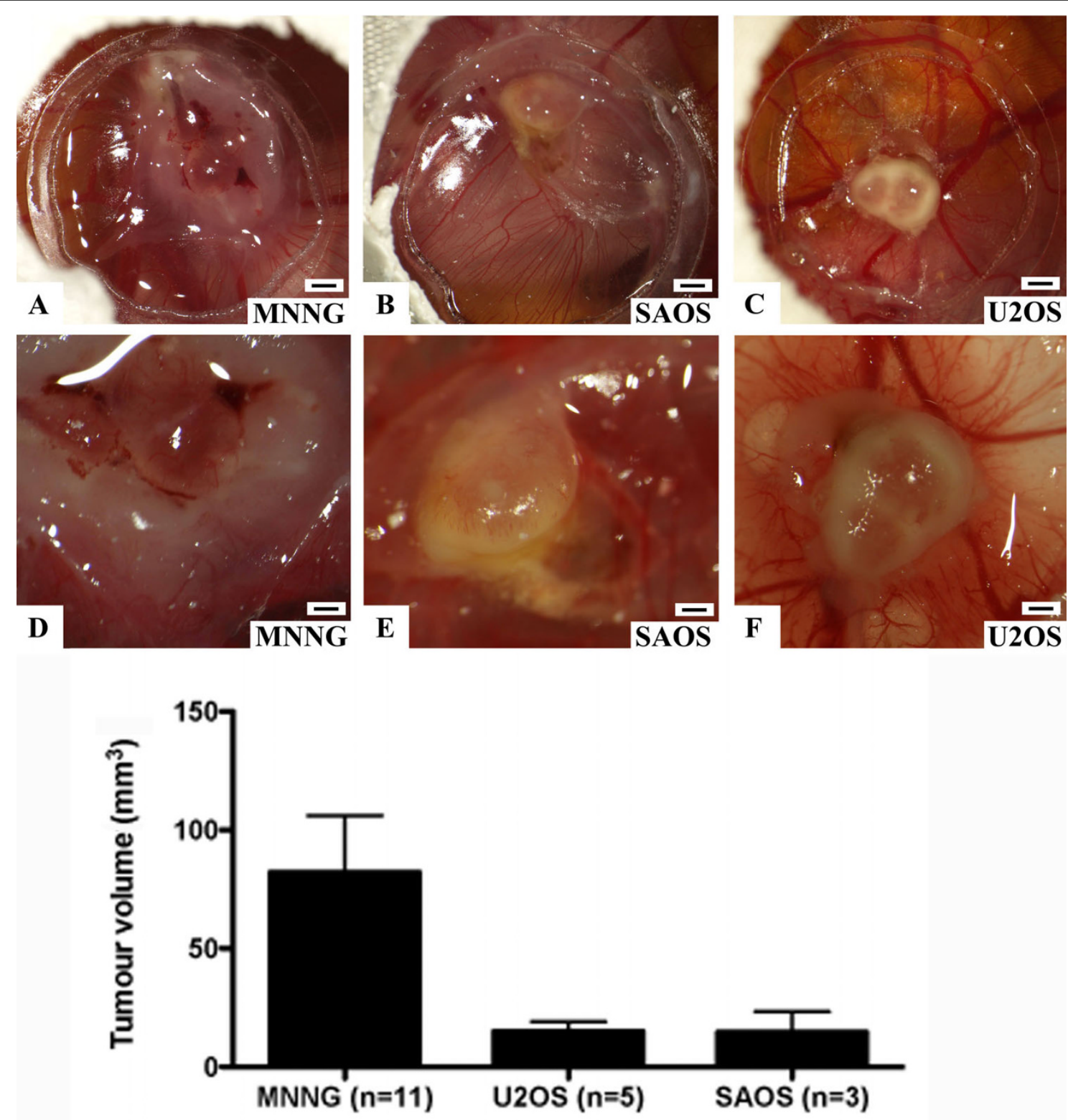

G

Cell line

Figure 1 Tumours of three different cell lines grown on the CAM. In vivo microscopy of tumours grown of indicated cell lines after 7 days of tumour growth. A - C: magnification 10x (scale bar $1 \mathrm{~mm}$ ), D - E: higher magnification (40x, scale bar $250 \mu \mathrm{m}$ ) of A - C. G: Graph illustrating the mean tumour volumes calculated by the following formula: $V=4 / 3^{*} \pi^{*} r^{3}(r=1 / 2 *$ square root of diameter $1 *$ diameter 2$)$. SEM $=$ standard error of mean.

might be due to the fact that each osteosarcoma cell line produces a differently composed extracellular matrix[21] and thus might have a different potential to degrade the CAM tissue. Possibly only the more aggressive cell lines are able to invade the CAM and induce angiogenesis, which is essential for tumour growth. The MNNG-HOS cell line is derived from HOS cells by treatment with the carcinogenic nitrosamine MNNG[25], and was shown to have a high degree of similarity but also some characteristic differences from the maternal cell line[22] that did not grow well in our model. The fact that a significantly higher mortality rate was seen after grafting of SAOS and U2OS cells (both reliably formed tumours) may be due to tumour cell dissemination in the embryo or secretion of factors which cause blood coagulation. Secretion of such molecules by cancer cells is favoured 


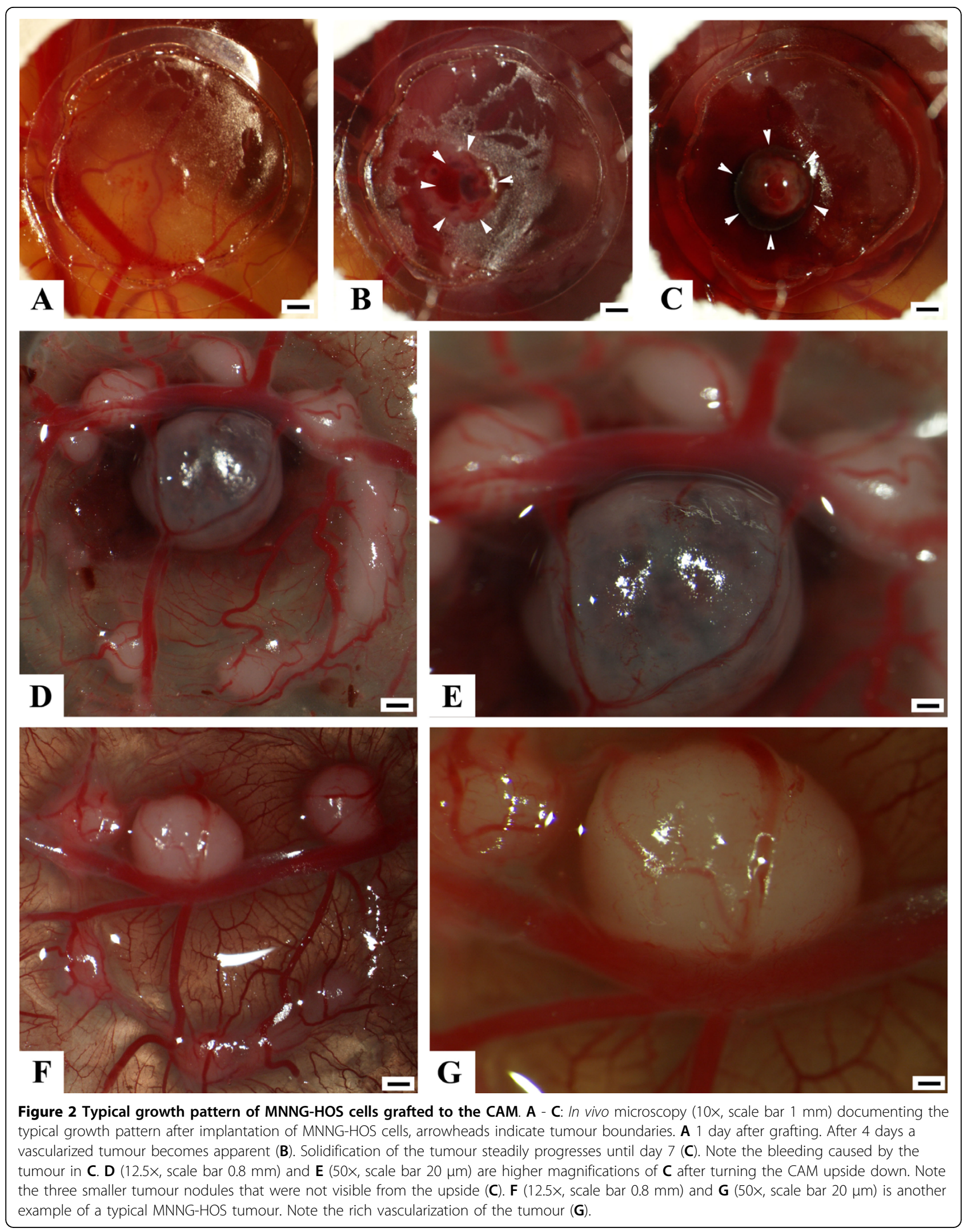




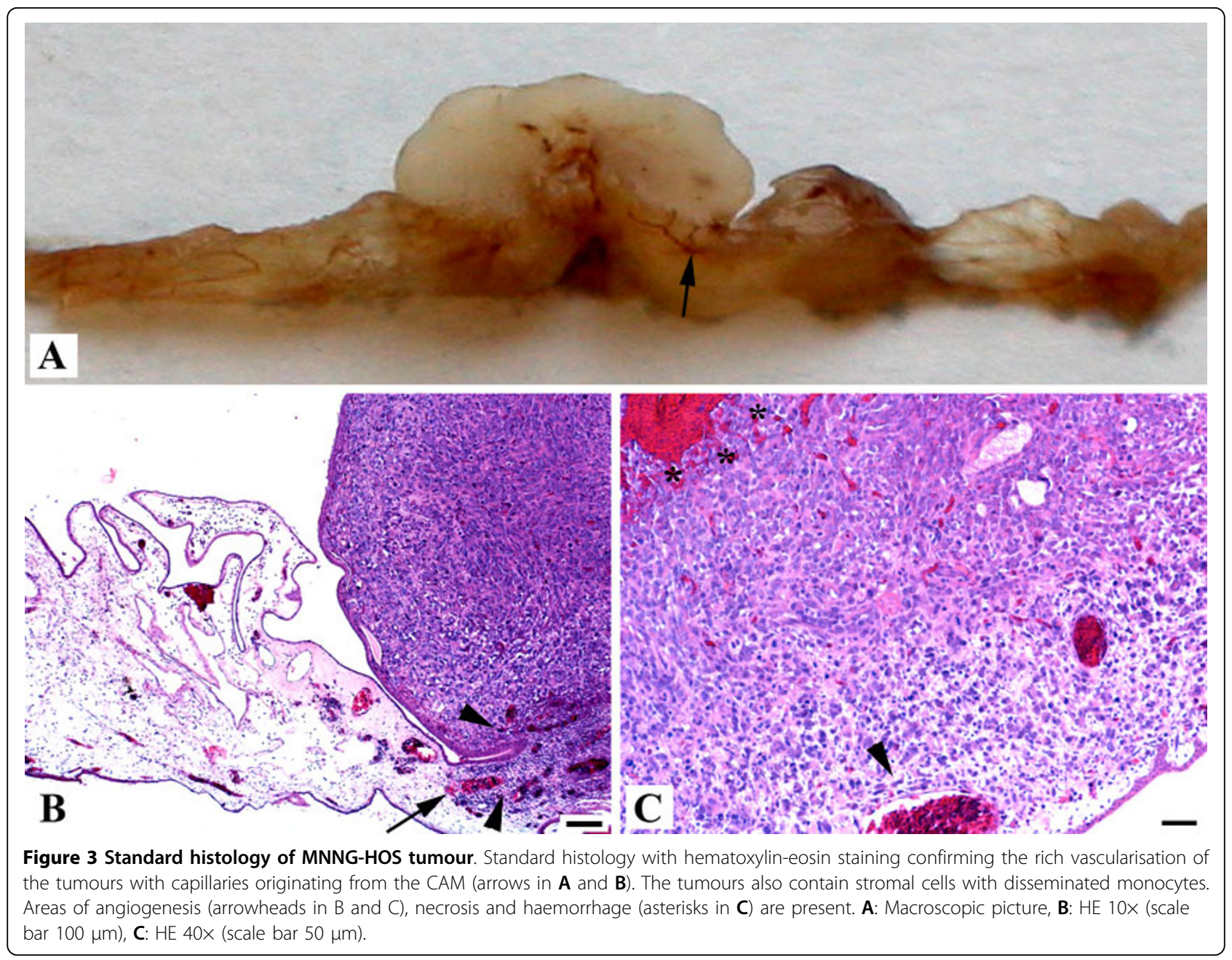

under metabolic stress such as hypoxia[26], a condition which might well occur during tumour cell implantation on the CAM. Tsuchiya et al.[20] examined 24 human tumour cell lines for their potential to form liver metastases after injecting them into a larger CAM vessel. They have shown that, among others, the MNNG-HOS cells proliferated in the liver. The metastatic potential of osteosarcoma cell lines (143B cells and to a lesser extent MNNG-HOS cells) has also been shown in an orthotopic mouse model[27] as well as in chick embryos after intravascular injection in CAM veins[28]. Thus, this model might also serve to study the development of distant metastases. Pulmonary metastases are very common in osteosarcoma and are the typical cause of death in human[1]. Also speculative at this point, they might also be responsible for the significantly higher death rate in the U2OS and SAOS treated embryos in our study.

The MNNG-HOS cells might be most suitable for further inhibition studies in our model, since this line reliably simulated key features of human osteosarcoma growth such as angiogenesis, necrosis and haemorrhage.
Osteoid formation however, did not occur in this model. This might be due to the lack of mature bone in the developing chick embryo or due to the short time span of only 7 days of tumour growth. The experimental osteosarcoma described here are hybrid tumours: they develop out of human cells and secondarily get invaded by newly formed chicken capillaries and stromal cells, therefore allowing further studies aiming at the molecular characterization of osteosarcoma angiogenesis. It might for example be possible to separately study gene expression in the newly formed vessels using Affymetrix chicken GeneChips, in parallel with human GeneChips, which will measure gene expression in the tumour cells. This could lead to the development of new antitumour drugs. The CAM model also is an attractive tool to follow the fate and visualize microscopically the behaviour of the grafted cells[14]. In vivo microscopy is possible at every time point during the growth process, thus allowing direct observations of tumour development and its reactions to intravascular or topical application of anticancer drugs. Additionally, intravital videomicroscopy of 
the chorioallantoic microcirculation enables studies focussing on metastasis formation. MacDonald et al. used epifluorescence to identify labelled B16F1 melanoma cells, and studied successive stages of metastasis formation in the CAM in vivo[29]. This might facilitate the screening of new therapeutic approaches[30] such as molecules targeting the RANK/RANKL/OPG axis[31].

A limit of this model is the short time span of only 7 days for tumour growth which might not have been long enough for the other cell lines to grow to bigger tumours. However, especially this time frame might be of importance for the development of metastases or tumour recurrence. These first steps are heavily dependent on invasion and angiogenesis, which is a promising target for new drugs against solid tumours, including osteosarcoma[32,33].

Our model could serve as a preclinical screening assay for anticancer molecules against osteosarcoma and therefore increase the speed and efficacy of the development of new drugs. More, the model is an excellent alternative to rodent models and fits perfectly into current recommendations of an ethically appreciable use of live animals in cancer research[34].

Last, the experimental tumour model on the CAM might be adapted for other malignant bone and soft-tissue tumours such as chondrosarcoma, Ewing's-sarcoma, malignant fibrous histiocytosis, and benign but locally aggressive lesions such as giant cell tumour of bone.

\section{Acknowledgements}

This work was supported by the EuroBoNet, a sixth framework priority programme: LSH-2004-2.2.0-1 - Uncommon cancers in adults and children. Special thanks go to Maryam Balke, MD, for critical review and correction of the manuscript.

\section{Author details}

${ }^{1}$ Department of Orthopaedic Surgery, University of Muenster, Muenster, Germany. ${ }^{2}$ Gerhard-Domagk-Institute of Pathology, University of Muenster, Muenster, Germany. ${ }^{3}$ Institute of Pathology, Paderborn, Germany. ${ }^{4}$ Department of Orthopaedic Surgery, Orthopädische Klinik Volmarstein Wetter, Germany. ${ }^{5}$ INSERM U920 - Laboratoire des mécanismes moléculaires de l'angiogenèse, University Bordeaux 1, Talence cedex, France.

\section{Authors' contributions}

MB performed all CAM experiments and drafted the manuscript. AN did all culturing of the cells and helped in drafting of the manuscript. CK and HB did the histology and analysis of the tumours. KA helped with analysis and interpretation of data. $\mathrm{MH}$ critically revised the manuscript and together with $M B$ is responsible for the study design. CG and GG participated in the study design and coordination and helped in interpretation of the data. All authors read and approved the final manuscript.

\section{Competing interests}

The authors declare that they have no competing interests.

Received: 30 November 2009

Accepted: 4 March 2010 Published: 4 March 2010

\section{References}

1. Winkler K, Beron G, Delling G, Heise U, Kabisch H, Purfurst C, Berger J, Ritter J, Jurgens $H$, Gerein V: Neoadjuvant chemotherapy of osteosarcoma: results of a randomized cooperative trial (COSS-82) with salvage chemotherapy based on histological tumor response. J Clin Oncol 1988, 6:329-337.

2. Casas-Ganem J, Healey $\mathrm{JH}$ : Advances that are changing the diagnosis and treatment of malignant bone tumors. Curr Opin Rheumatol 2005, 17:79-85.

3. Man TK, Lu XY, Jaeweon K, Perlaky L, Harris CP, Shah S, Ladanyi M, Gorlick R, Lau CC, Rao PH: Genome-wide array comparative genomic hybridization analysis reveals distinct amplifications in osteosarcoma. BMC Cancer 2004, 4:45.

4. Quan GM, Choong PF: Anti-angiogenic therapy for osteosarcoma. Cancer Metastasis Rev 2006, 25:707-713.

5. Kreuter M, Bieker R, Bielack SS, Auras T, Buerger H, Gosheger G, Jurgens $H$, Berdel WE, Mesters RM: Prognostic relevance of increased angiogenesis in osteosarcoma. Clin Cancer Res 2004, 10:8531-8537.

6. DeFouw DO, Rizzo VJ, Steinfeld R, Feinberg RN: Mapping of the microcirculation in the chick chorioallantoic membrane during normal angiogenesis. Microvasc Res 1989, 38:136-147.

7. Rahn H, Paganelli CV, Ar A: The avian egg: air-cell gas tension, metabolism and incubation time. Respir Physiol 1974, 22:297-309.

8. Javerzat S, Franco M, Herbert J, Platonova N, Peille AL, Pantesco V, De Vos J, Assou S, Bicknell R, Bikfalvi A, Hagedorn M: Correlating global gene regulation to angiogenesis in the developing chick extra-embryonic vascular system. PLoS One 2009, 4:e7856.

9. Folkman J: Angiogenesis: initiation and control. Ann N Y Acad Sci 1982 401:212-227.

10. Hagedorn M, Javerzat S, Gilges D, Meyre A, de Lafarge B, Eichmann A, Bikfalvi A: Accessing key steps of human tumor progression in vivo by using an avian embryo model. Proc Natl Acad Sci USA 2005, 102:1643-1648.

11. Decker S, Winkelmann W, Nies B, van Valen F: Cytotoxic effect of methotrexate and its solvent on osteosarcoma cells in vitro. J Bone Joint Surg Br 1999, 81:545-551.

12. Hagedorn M, Balke M, Schmidt A, Bloch W, Kurz H, Javerzat S, Rousseau B, Wilting J, Bikfalvi A: VEGF coordinates interaction of pericytes and endothelial cells during vasculogenesis and experimental angiogenesis. Dev Dyn 2004, 230:23-33

13. Murphy JB, Rous $P$ : The behavior of chicken sarcoma implanted in the developing embryo. J Exp Med 1912, 119-132.

14. Deryugina El, Quigley JP: Chick embryo chorioallantoic membrane model systems to study and visualize human tumor cell metastasis. Histochem Cell Biol 2008, 130:1119-1130.

15. Hagedorn M, Wilting J: Chick chorioallantoic membrane assay: growth factor and tumor-induced angiogenesis and lymphangiogenesis Berlin, Heidelberg, Germany: Springer 2004.

16. Saidi A, Javerzat S, Bellahcene A, De Vos J, Bello L, Castronovo V, Deprez M, Loiseau $H$, Bikfalvi A, Hagedorn M: Experimental anti-angiogenesis causes upregulation of genes associated with poor survival in glioblastoma. Int J Cancer 2008, 122:2187-2198

17. Saidi A, Hagedorn M, Allain N, Verpelli C, Sala C, Bello L, Bikfalvi A, Javerzat S: Combined targeting of interleukin- 6 and vascular endothelial growth factor potently inhibits glioma growth and invasiveness. Int $J$ Cancer 2009, 125:1054-1064.

18. Kunzi-Rapp K, Genze F, Kufer R, Reich E, Hautmann RE, Gschwend JE: Chorioallantoic membrane assay: vascularized 3-dimensional cell culture system for human prostate cancer cells as an animal substitute model. J Urol 2001, 166:1502-1507.

19. Deryugina El, Zijlstra A, Partridge JJ, Kupriyanova TA, Madsen MA, Papagiannakopoulos T, Quigley JP: Unexpected effect of matrix metalloproteinase down-regulation on vascular intravasation and metastasis of human fibrosarcoma cells selected in vivo for high rates of dissemination. Cancer Res 2005, 65:10959-10969.

20. Tsuchiya $Y$, Endo $Y$, Sato H, Okada Y, Mai M, Sasaki T, Seiki M: Expression of type-IV collagenases in human tumor cell lines that can form liver colonies in chick embryos. Int J Cancer 1994, 56:46-51.

21. Pautke C, Schieker M, Tischer T, Kolk A, Neth P, Mutschler W, Milz S: Characterization of osteosarcoma cell lines MG-63, Saos-2 and U-2 OS in comparison to human osteoblasts. Anticancer Res 2004, 24:3743-3748.

22. Ottaviano L, Schaefer KL, Gajewski M, Huckenbeck W, Baldus S, Rogel U, Mackintosh C, de Alava E, Myklebost O, Kresse SH, et al: Molecular characterization of commonly used cell lines for bone tumor research: A trans-European EuroBoNet effort. Genes Chromosomes Cancer 2009. 
23. Rodan SB, Imai Y, Thiede MA, Wesolowski G, Thompson D, Bar-Shavit Z, Shull S, Mann K, Rodan GA: Characterization of a human osteosarcoma cell line (Saos-2) with osteoblastic properties. Cancer Res 1987, 47:4961-4966.

24. Niforou KM, Anagnostopoulos AK, Vougas K, Kittas C, Gorgoulis VG, Tsangaris GT: The proteome profile of the human osteosarcoma U2OS cell line. Cancer Genomics Proteomics 2008, 5:63-78.

25. Rhim JS, Park DK, Arnstein P, Huebner RJ, Weisburger EK, Nelson-Rees WA: Transformation of human cells in culture by $\mathrm{N}$-methyl- $\mathrm{N}^{\prime}-$ nitro- $\mathrm{N}$ nitrosoguanidine. Nature 1975, 256:751-753.

26. Denko NC, Giaccia AJ: Tumor hypoxia, the physiological link between Trousseau's syndrome (carcinoma-induced coagulopathy) and metastasis. Cancer Res 2001, 61:795-798.

27. Luu HH, Kang Q, Park JK, Si W, Luo Q, Jiang W, Yin H, Montag AG, Simon MA, Peabody TD, et al: An orthotopic model of human osteosarcoma growth and spontaneous pulmonary metastasis. Clin Exp Metastasis 2005, 22:319-329.

28. Haeckel C, Krueger S, Roessner A: Antisense inhibition of urokinase: effect on malignancy in a human osteosarcoma cell line. Int J Cancer 1998, 77:153-160.

29. MacDonald IC, Schmidt EE, Morris VL, Chambers AF, Groom AC: Intravital videomicroscopy of the chorioallantoic microcirculation: a model system for studying metastasis. Microvasc Res 1992, 44:185-199.

30. Khanna C: Novel targets with potential therapeutic applications in osteosarcoma. Curr Oncol Rep 2008, 10:350-358.

31. Mori K, Berreur M, Blanchard F, Chevalier C, Guisle-Marsollier I, Masson M, Redini F, Heymann D: Receptor activator of nuclear factor-kappaB ligand (RANKL) directly modulates the gene expression profile of RANK-positive Saos-2 human osteosarcoma cells. Oncol Rep 2007, 18:1365-1371.

32. Almog N, Henke V, Flores L, Hlatky L, Kung AL, Wright RD, Berger R, Hutchinson L, Naumov GN, Bender E, et al: Prolonged dormancy of human liposarcoma is associated with impaired tumor angiogenesis. Faseb J 2006, 20:947-949.

33. Ma WW, Adjei AA: Novel agents on the horizon for cancer therapy. CA Cancer I Clin 2009, 59:111-137.

34. Russell WMS, Burch RL: The Principles of Humane Experimental Technique Potters Bar, UK: Universities Federation for Animal Welfare (UFAW), New 1992.

doi:10.1186/1756-0500-3-58

Cite this article as: Balke et al: Morphologic characterization of osteosarcoma growth on the chick chorioallantoic membrane. BMC Research Notes 2010 3:58.

\section{Submit your next manuscript to BioMed Central and take full advantage of:}

- Convenient online submission

- Thorough peer review

- No space constraints or color figure charges

- Immediate publication on acceptance

- Inclusion in PubMed, CAS, Scopus and Google Scholar

- Research which is freely available for redistribution

Submit your manuscript at www.biomedcentral.com/submit 